\title{
Awareness of the role of cardiovascular risk factors and their prevention from the perspective of Tricity adolescents
}

\author{
Dawid Ostrówka*, Marta Jancewicz* , Anna Komand, Maria Nowak, Marcin Łubiarz, \\ Magdalena Furtak, Anna Szyndler, Jacek Wolf, Krzysztof Narkiewicz
}

Department of Hypertension and Diabetology Medical University of Gdańsk, Poland

\begin{abstract}
Introduction. Arterial hypertension (HT) affects 10.4 million adult Poles, and the blood pressure (BP) control rate is only $26 \%$. Beyond any doubt, high blood pressure results in cardiovascular (CV) target organ damage, which markedly influences national healthcare programs. Childhood introduced cardiovascular prophylaxis offers opportunities to decrease incident HT and delay or even eliminate its consequences. Therefore we have decided to study the level of knowledge on HT and CV disease (CVD) among random 1st and 2nd grade high school students in Tricity, Poland.

Material and methods. Questionnaire-based study was conducted voluntarily in two selected high schools of the Tricity agglomeration, Poland, in 2000 and repeated in 2016. All participants were presented with a 38-item questionnaire on cardiovascular risk factors knowledge as well as students' health habits.

Results. Studied group consisted of 615 students (57.6\% females) at the age of 16, mean BMI $20.89 \pm 2.95 \mathrm{~kg} / \mathrm{m}^{2}$ (78\% BMI norm). The evaluation of the several habits in two time-points was as follows: additional salt intake was reported by $38.3 \%$ vs. $35.1 \%$ adolescents in 2000 and 2016 , respectively; $\mathrm{p}=0.43$, dining in fast food restaurants at least once a week: $13.9 \%$ vs. $44.8 \%$; $2000 / 2016$; $p<0.01$; hours per week spent on physical activity: $5.6 \pm 4.4$ vs. $5.5 \pm 4.5 ; \mathrm{p}=0.85$; students who never drank alcohol: $19.7 \%$ vs. $31.1 \% ; \mathrm{p}<0.01$; cigarettes ever smoking: $39.6 \%$ vs. $21.2 \%$; $<<0.01$; regular smokers: $10.2 \%$ vs. $4.1 \%$; $<<0.05$. The awareness of $\mathrm{CV}$-preventive measures such as body weight reduction was presented by $88.1 \%$ vs. $93.9 \%$ students in 2000 vs. $2016 ; \mathrm{p}=0.01$; regular physical activity $92.6 \%$ vs. $97.1 \%$; $\mathrm{P}=0.01$, limiting smoking and alcohol consumption $84.2 \%$ vs. $91.2 \% ; \mathrm{p}=0.01$; salt reduction: $62.6 \%$ vs. $82.3 \% ; \mathrm{p}<0.001$. Interestingly, in 2016 the majority of students identified myocardial infarction as a consequence of AH $92.4 \%$, which was markedly less evident in case of stroke and kidney disease $(46.2 \%$, and $28 \%$, respectively).

Conclusion. Although the awareness of negative consequences of $\mathrm{HT}$ and other CV-risk factors has grown over the past 15 years, the implementation of this knowledge is insufficient among high-school adolescents.

key words: health literacy, adolescents, CVD risk factors, salt, diet, smoking, physical activity
\end{abstract}

Arterial Hypertens. 2017, vol. 21, no. 1, pages: 51-59

DOI: $10.5603 / A H .2017 .0007$

*joint first authors

Address for correspondence: Anna Szyndler, MD

Department of Hypertension and Diabetology

Medical University of Gdańsk, Poland

ul. Dębinki 7C, 80-952 Gdańsk, Poland

e-mail: anna@gumed.edu.pl 


\section{Introduction}

Arterial hypertension affects approximately one third of Polish adult population [1]. The prevalence of systemic arterial hypertension $(\mathrm{AH})$ continues to rise, especially in young adults [2]: in the United States it has reached $19 \%$ in 2008 in the 24-32 age group, according to the Add Health study [3]. The problem of the increased blood pressure becomes also considerable among adolescents. According to the Polish survey OLA/OLAF, which provided blood pressure percentiles charts for Polish adolescent population, $6.2 \%$ of children between $10-20$ years of age presented with hypertension [4]. Arterial hypertension in young adults is mainly caused by habits instilled in childhood such as increased salt and fat consumption, and using recreational substances such as alcohol and cigarettes [5]. The role of these risk factors is well established, being modifiable at the same time.

The prevalence of overweight in Polish children population ranges between 2 and $12 \%$ depending on age and sex. These numbers place us into the medium to high prevalence level compared with other European countries [6]. Childhood ponderosity is well established risk factor for high adult blood pressure [7]. Although, there are many actions towards promotion of physical activity and weight reduction, the problem of increasing obesity prevalence among children is still unsolved.

Excessive salt intake poses as a risk factor for development and progression of hypertension. Numerous studies have shown that the global salt consumption is very high, exceeding the physiological need up to ten times [8]. This tendency described for the adult population is similar among adolescents. It has also been proved that the salt consumption increases with aging [9].

Another factor which may affect the level of blood pressure in adolescence is recreational substances usage. There is a lack of recent studies on the prevalence of smoking among children. In 2002, 9-18\% of Polish 14-15 years olds admitted to regular smoking, what outnumbers the prevalence from earlier studies [10]. In the questionnaire-based study SOPKARD 15 Programme conducted ten years ago, 7.6\% girls and $8.5 \%$ boys declared every-day cigarettes smoking [11]. There is also an increase in e-cigarette use among Polish students [12]. Tobacco consumption usually begins in adolescence and early smoking initiation is related to stronger nicotine dependence and problems with smoking cessation in adulthood [13]. The problem with increasing alcohol consumption among teenagers has also been observed. In Warsaw adolescents' population, the alcohol intake was significantly higher in 2004 compared to 1988 , and the increasing tendency was noted among both boys and girls [14]. Analogously to smoking, alcohol intake by adolescents may determine early development of alcohol dependence [15].

Instilling healthy habits in adolescents appears to be a crucial factor in overall cardiovascular disease (CVD) prevention. Therefore, we evaluated changes in healthy lifestyle habits and assessed the knowledge on HT and CVD risk factors, as well as the awareness of CV-preventive measures within the population of Tricity adolescents.

\section{Material and methods}

Questionnaire-based study was conducted voluntarily in selected high schools of the Tricity agglomeration, Poland. Responsible relatives of the participants as well as the subjects themselves gave an informed consent. The study conformed to the standards set by the Declaration of Helsinki. The Ethical Committee of the Medical University of Gdansk approved the study (NKEBN/114/2016).

All participants were presented with a 38-item questionnaire developed by A. Sz. (Fig. 1) which was completed individually in Polish, during a class.

Students were evaluated two times. In 2000 we surveyed anonymously school adolescents at the age of $16(\mathrm{n}=201,54.2 \%$ females; 1 student did not specify sex) attending the first, and the second high school grade. The procedure was replicated in 2016 and their coevals participated $(\mathrm{n}=410 ; 59.3 \%$ females; 3 students did not specify their sex).

The questionnaire was composed of two main domains related to (1) the awareness of cardiovascular risk factors, and (2) self-reported lifestyle habits such as physical activity, dietary approach, and substances use. Students were also asked about basic anthropometrical data i.e. weight (actual/declared and desired), and height, as well as their parents' CVD history. Later anthropometrics were compared to Polish adolescents-specific percentile charts [16].

All data were tabulated in MS Excel and processed in statistical package (Statistica 10, Statsoft, Poland licensed to GUMed). The questionnaire answers between the year of 2000 and 2016 were compared with the Chi-squared test. Continuous variables were compared with unpaired t-test, p-value less than 0.05 was considered statistically significant for all comparisons.

\section{Results}

In total, six hundred fifteen students $(72.8 \%$ of the eligible subjects) agreed to participate in the survey. 


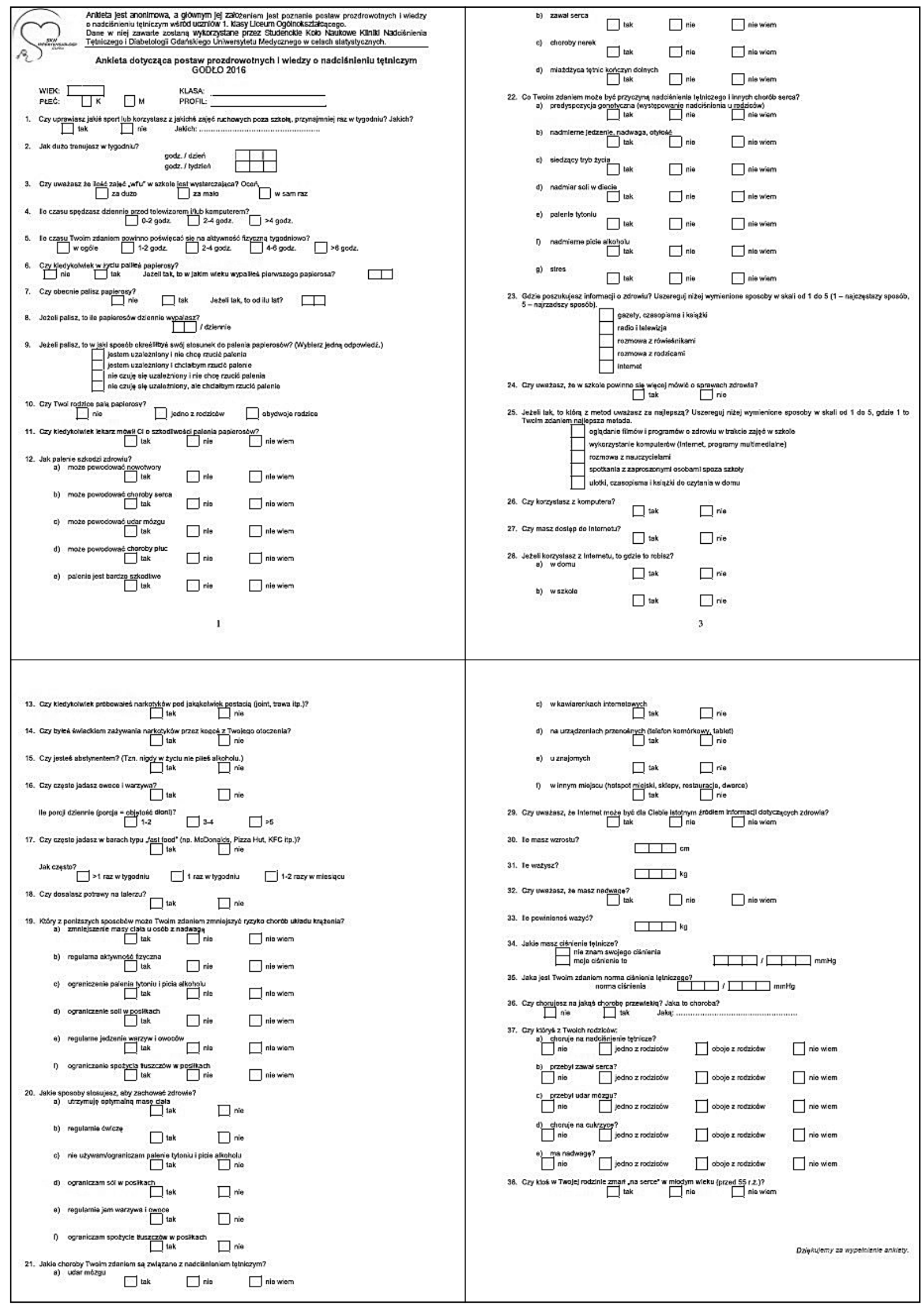

Figure 1. The original questionnaire presented to students (in Polish) 


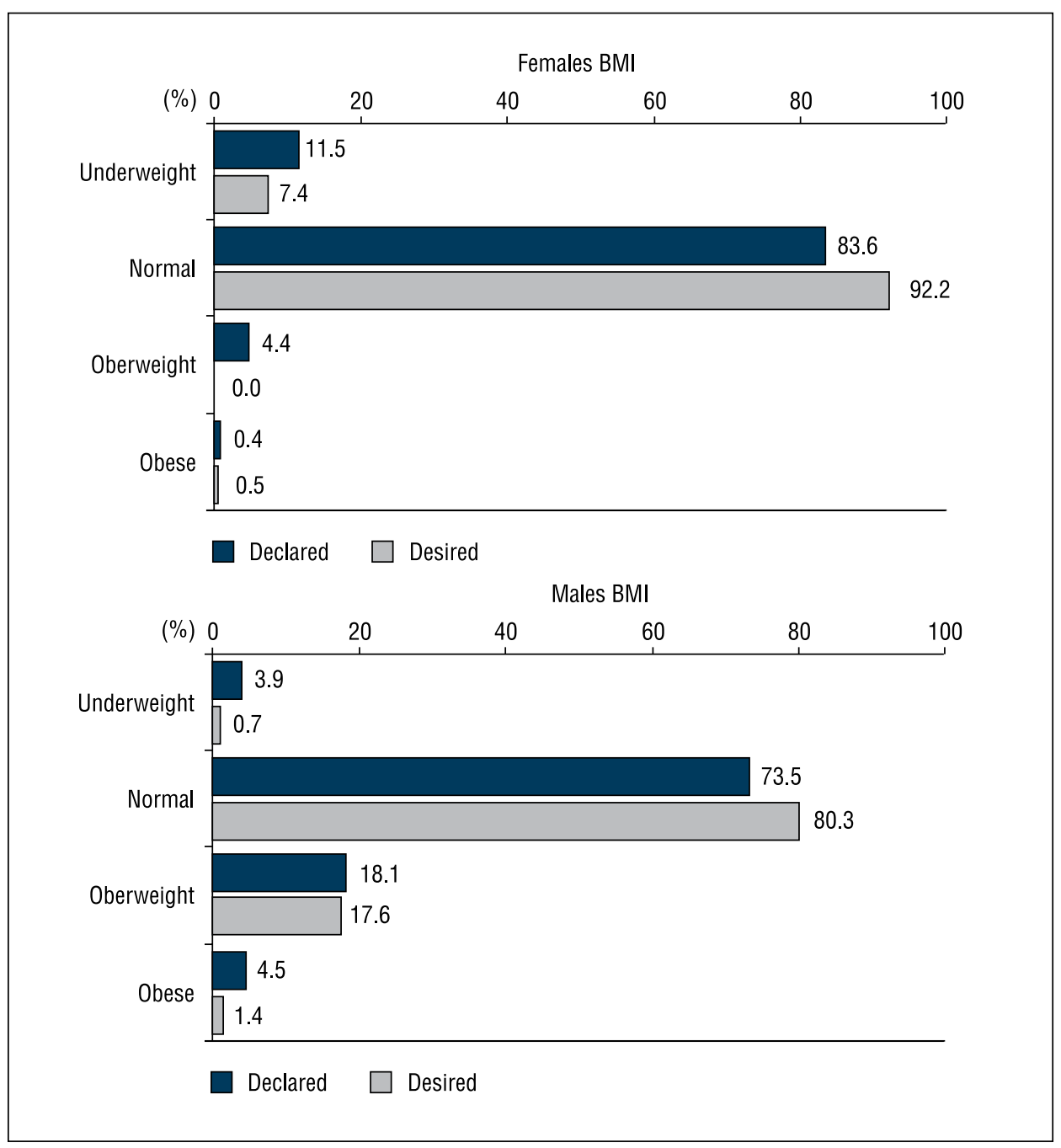

Figure 2. The comparison of declared vs. desired body mass. BMI category according to percentiles (Kułaga et al.)

The response rate varied between $93 \%$ and $100 \%$ depending on the presented question. Out of 38 requested answers, twelve questions were related to social aspects which were not a primary goal of this analysis.

The distribution of body mass index based on declared weight is depicted in Figure 2. Seventy eight percent of surveyed children were characterized by normal BMI as referred to percentile charts. Interestingly, females vs. males were more likely to declare desired body weight within underweight range $(12 \%$ vs. $0.7 \% ; \mathrm{p}<0.05)$. Concurrently, boys would have expected to have their body weight exceeding normal values $(19 \%$ vs. $0.5 \%$ as preferred by their female counterparts; $\mathrm{p}<0.05)$.

\section{Dietary habits}

Additional salt intake (meals seasoning) was declared by a similar proportion of teenagers at two time- points $(38.3 \%$ vs. $35.1 \%$ in the year of 2000 and 2016 , respectively; $p=0.43$ ). The subanalysis limited to those adolescents who add salt to their meals showed that $76.8 \%$ of children in 2016 knew that salt reduction may be protective against hypertension. Twenty percent of them had at least one of their parents diagnosed with hypertension.

Along with increasing awareness on detrimental impact of salt on CV system (75.8\% vs. $52.9 \%$ associated excessive salt intake with CVD in 2000 and 2016, respectively; $\mathrm{p}<0.01$ ), there was a growing recognition of potential CV benefits resulting from salt reduction (Tab. I).

Although there was a moderate increase in vegetables/fruits consumption observed between the two time-points $(\mathrm{p}=0.02)$, concurrently, there was a three-fold increase in declared regular fast-food dining $(p<0.01)$. Interestingly, this unfavorable trend accompanied growing recognition of the fact 
Table I. Lifestyle, diet and substances use

\begin{tabular}{|c|c|c|c|}
\hline & 2000 & 2016 & P-value \\
\hline \multicolumn{4}{|l|}{ Lifestyle and activity: } \\
\hline Percentage of students who do sports out of school & $51.0 \%$ & $73.4 \%$ & $<0.01$ \\
\hline Number of hours per week of physical activity & $5.6 \pm 4.4$ & $5.5 \pm 4.5$ & 0.85 \\
\hline Students who practice 3 or more types of sport disciplines & $3.9 \%$ & $10 \%$ & 0.05 \\
\hline Students who recognize physical activity as a mean to reduce risk CVD & $92.6 \%$ & $97.1 \%$ & 0.01 \\
\hline Students who use computer or TV set for 2 or more hours per day & $46.3 \%$ & $47.2 \%$ & 0.82 \\
\hline Students who use computer or TV set for 4 or more hours per day & $9.3 \%$ & $14 \%$ & 0.09 \\
\hline Students who consider sedentary lifestyle to cause hypertension & $65.4 \%$ & $85.3 \%$ & $<0.01$ \\
\hline \multicolumn{4}{|l|}{ Dietary approach: } \\
\hline Students who consider salt excess in meals as a risk factor of HT and CVD & $52.9 \%$ & $75.8 \%$ & $<0.01$ \\
\hline Students who consider reduction of salt in meals to decrease risk of CVD & $62.6 \%$ & $82.3 \%$ & $<0.01$ \\
\hline Percentage of students who add salt to their meals & $38.3 \%$ & $35.1 \%$ & 0.43 \\
\hline Salt-users with hypertensive parent & - & $20.0 \%$ & N.A. \\
\hline Salt-users who consider salt in diet as a risk factor of HT and CVD & - & $71.1 \%$ & N.A. \\
\hline Salt-users who consider salt reduction to decrease risk of CVD & - & $76.8 \%$ & N.A. \\
\hline Students who consider regular consumption of fruits/vegetables to decrease risk of CVD & $79.3 \%$ & $83.1 \%$ & 0.25 \\
\hline Students who declare regular eating of fruit and vegetables & $80.1 \%$ & $87.3 \%$ & 0.02 \\
\hline Students dinning in fast food restaurants at least once a week & $13.9 \%$ & $44.8 \%$ & $<0.01$ \\
\hline Students who consider reduction of fats in meals to decrease risk of CVD & $84.7 \%$ & $86.2 \%$ & 0.61 \\
\hline Students who declare to reduce amount of fats in their diet & $57.4 \%$ & $55.5 \%$ & 0.65 \\
\hline Students who consider excessive eating, overweight and obesity to cause hypertension & $86.3 \%$ & $93.9 \%$ & $<0.01$ \\
\hline \multicolumn{4}{|l|}{ Substances: } \\
\hline Students who never drank alcohol & $19.7 \%$ & $31.1 \%$ & $<0.01$ \\
\hline Students who consider alcohol to cause hypertension & $57.8 \%$ & $67.7 \%$ & 0.02 \\
\hline Students who tried smoking in the past & $39.6 \%$ & $21.2 \%$ & $<0.01$ \\
\hline Average age of smoking initiation & $12.9 \pm 1.9$ & $14.6 \pm 1.4$ & 0.02 \\
\hline Current smokers & $10.2 \%$ & $4.2 \%$ & $<0.01$ \\
\hline $\begin{array}{l}\text { Current smokers with at least one smoking parent vs. non-smokers with at least one parent } \\
\text { smoking }\end{array}$ & & $\begin{array}{l}47.1 \% \\
22.6 \%\end{array}$ & $0.02^{*}$ \\
\hline Students informed by health professionals about negative effects of smoking & $36.0 \%$ & $43.3 \%$ & 0.08 \\
\hline \multicolumn{4}{|l|}{ Students who consider tobacco smoking to cause: } \\
\hline Hypertension & $64.9 \%$ & $64.8 \%$ & 0.98 \\
\hline Cancer & $94.6 \%$ & $98.0 \%$ & 0.01 \\
\hline Heart diseases & $95.6 \%$ & $82.4 \%$ & $<0.01$ \\
\hline Stroke & $15.6 \%$ & $39.9 \%$ & $<0.01$ \\
\hline Lung diseases & $98.0 \%$ & $98.5 \%$ & 0.65 \\
\hline Students who consider reduction of smoking and alcohol to decrease risk of CVD & $84.2 \%$ & $91.2 \%$ & $<0.01$ \\
\hline
\end{tabular}

$p$-value corresponds to $\chi^{2}$ test performed to delineate the differences between 2000 and 2016

${ }^{*} \mathrm{p}$-value refers to the difference between non-smokers and current smokers with at least one parent smoking

that excessive fat consumption contributes to the development of hypertension ( $\mathrm{p}<0.01$; Tab. I).

No significant change in the attitude towards fat limitation in the diet was evident between 2000 and 2016 ( $\mathrm{p}=0.65$; Tab. I).

\section{Physical activity}

As compared to the year of 2000 there was a marked increase in the interest in various sport-activities. $73.1 \%$ of students in 2016 declared out-of-school activity at least once a week compared with $48 \%$ in 
Table II. The Awareness of CVD risk factors and corresponding real-life implementation

\begin{tabular}{|l|c|c|c|c|c|c|}
\hline & \multicolumn{3}{|c|}{$\begin{array}{c}\text { Students who consider the following factors } \\
\text { to reduce CVD risk }\end{array}$} & \multicolumn{3}{c|}{$\begin{array}{c}\text { Students who regularly practice the following } \\
\text { activity }\end{array}$} \\
\hline & 2000 & $\mathbf{2 0 1 6}$ & p-value & $\mathbf{2 0 0 0}$ & $\mathbf{2 0 1 6}$ & p-value \\
\hline Body weight reduction & $88.1 \%$ & $93.9 \%$ & 0.01 & $65.2 \%$ & $81.1 \%$ & $<0.001$ \\
\hline Regular physical activity & $92.6 \%$ & $97.1 \%$ & 0.01 & $62.7 \%$ & $68.6 \%$ & 0.15 \\
\hline Limiting smoking and alcohol consumption & $84.2 \%$ & $91.2 \%$ & 0.01 & $82.9 \%$ & $91.1 \%$ & $<0.01$ \\
\hline Reducing salt in meals & $62.6 \%$ & $82.3 \%$ & $<0.001$ & $49.0 \%$ & $61.7 \%$ & $<0.01$ \\
\hline Regular fruit and vegetable consumption & $79.3 \%$ & $83.1 \%$ & 0.25 & $80.1 \%$ & $87.3 \%$ & 0.02 \\
\hline Fat reduction in meals & $84.7 \%$ & $86.2 \%$ & 0.61 & $57.4 \%$ & $55.5 \%$ & 0.65 \\
\hline
\end{tabular}

p-value corresponds to $\chi^{2}$ test performed to delineate the differences between 2000 and 2016

Table III. Students correctly identifying smoking-related diseases

\begin{tabular}{|l|c|c|c|}
\hline \multicolumn{1}{|c|}{ Condition } & $\mathbf{2 0 0 0}$ & $\mathbf{2 0 1 6}$ & P-value \\
\hline Cancer & $94.6 \%$ & $98.0 \%$ & 0.01 \\
\hline Heart diseases & $95.6 \%$ & $82.4 \%$ & $<0.01$ \\
\hline Stroke & $15.6 \%$ & $39.9 \%$ & $<0.01$ \\
\hline Lung diseases & $98.0 \%$ & $98.5 \%$ & 0.65 \\
\hline
\end{tabular}

p-value corresponds to $\chi^{2}$ test performed to delineate the differences between 2000 and 2016

2000 ( $\mathrm{p}<0.01$; Tab. I). Moreover, a higher proportion of teenagers identified regular exercises as an effective CV-prevention measure ( $92.3 \%$ vs. $97.0 \%$ in 2000 vs. 2016, respectively; $\mathrm{p}<0.01$; Tab. II). Surprisingly, the interest in sports was not followed by the greater amount of time spent on physical activity per week (approx. 5.5 hrs/week; p = 0.85, Tab. I). The detailed distribution of sport intensity is presented in Table I.

\section{Recreational substances}

There was an increase of proportion of students who declared that they refrain from first-ever alcohol use. In 2016 the alcohol abstinence was declared by approximately $1 / 3$ of students which contrasts with $1 / 5$ observed 15 years earlier $(\mathrm{p}<0.05$; Tab. I). This favorable trend aligned with $10 \%$ net increase of students who recognize alcohol as a CV-risk factor $(\mathrm{p}<0.05$; Tab. I).

There was also a $6 \%$ points drop of cigarettes smokers observed in time. Only 17 students (4.2\%) in 2016 declared to be a current smoker. Apparently, the recognition of detrimental effects of smoking habit resulted in older age of first contact with cigarettes, which equaled $14.6 \pm 1.35$ years of age in 2016 (approx. 1.6 years later as compared to the year of 2000; $p=0.02$, Tab. I). Additionally, less students reported to ever smoke a cigarette $(21.2 \%$ vs. $39.6 \%$, in 2016 vs. 2000 , respectively; $\mathrm{p}<0.01$ ). Although there was a common understanding of a causative
Table IV. Students correctly identifying target organ damage in hypertension

\begin{tabular}{|l|c|c|c|}
\hline & $\mathbf{2 0 0 0}$ & $\mathbf{2 0 1 6}$ & P-value \\
\hline Stroke & $14.4 \%$ & $46.2 \%$ & $<0.001$ \\
\hline Myocardial infarction & $83.9 \%$ & $92.4 \%$ & 0.001 \\
\hline Kidney diseases & $8.9 \%$ & $28.0 \%$ & $<0.001$ \\
\hline Lower limb atherosclerosis & $49.5 \%$ & $73.7 \%$ & $<0.001$ \\
\hline
\end{tabular}

role of cigarettes smoking in the development of lung cancer (Tab. III), at the same time there was an unacceptably low recognition of this habit as a stroke risk factor (Tab. III). There was a remarkable coincidence related to generation-driven smoking pattern. Among 17 students who were current smokers almost half has at least one parent smoking (Tab. I) compared to $22.6 \%$ of non-smokers with at least one parent smoking $(\mathrm{p}=0.02)$.

\section{CVD risk factors and health-promoting behavior}

Responses to several questions related to the awareness of selected CV-risk factors and its role in the development of CVD are summarized in Tables II, III, and IV.

\section{Discussion}

In a year 2000 and 2016, a questionnaire-based study was conducted among first and second grade pupils in randomly-selected high schools of the Tricity agglomeration, Poland. Students were asked to complete a 38-item questionnaire aiming at assessing their knowledge on cardiovascular risk factors as well as to evaluate the prevalence of healthy everyday behaviors (physical activity, substance use, diet). Our findings indicate that although the awareness of neg- 
ative consequences of $\mathrm{HT}$ and other $\mathrm{CV}$-risk factors has grown over the past 15 years, the implementation of this knowledge is insufficient among high-school adolescents.

\section{Body weight}

In our population we noted higher prevalence of declared overweight and obesity in boys compared to girls $(22.6 \%$ vs. $4.8 \%$, respectively), whereas the underweight was more common among girls (11.5\%, vs. 3.9\% observed in men). Those results are consistent with the results of two other Polish surveys, which reported the higher risk of excessive body weight in boys as compared with girls $(12.9 \%$ vs. $8.7 \%$ for boys and girls, respectively; $\mathrm{p}<0.001)$, especially in urban areas as well as higher frequency of underweight in girls in comparison with boys $[17,18]$. Interestingly, the prevalence of overweight/ /obesity in Tricity high-school pupils is at similar level as the abnormal weight prevalence described by Dereziński et al. in younger urban-rural high schools pupils (22\% in 2014) [19].

However, it is worth to mention that the prevalence of normal/abnormal body weight and BMI were calculated from declared data, not from actual measured ones, therefore are not free from self reported bias. The German research showed that boys and girls tend to under-report their weight. Based on self-reports, the prevalence was $9.7 \%$ for underweight and $15.1 \%$ for overweight, according to measured data the corresponding rates were $7.5 \%$ and $17.7 \%$, respectively [20].

The analysis of body size perception showed that almost all girls with higher than normal declared BMI, indicated normal body weight as desired, whereas boys tended to point to higher values of body weight than normal. This confirms the fact noted by Scandinavian researches that men tend to underestimate their body weight more often than women, allowing them for higher level of satisfaction from their body size.

\section{Salt}

Salt intake results in an increased blood pressure, which has been further supported by epidemiological data showing that excessive salt-use is associated with higher HT rates. The WHO recommendations for salt intake are established at the level of $5 \mathrm{~g}$ per day [21]. However, there is a common tendency to exceed this limits which is also observed in adolescents [9]. The main sources of sodium in adolescents' diet are cereal and cereal products (41\%), followed by meet and milky products, whereas the fast food constitutes $9 \%$ of salt source [22]. What might be disturbing is that proportions of students who put extra salt into their meals has not changed significantly over the course of the past 15 years. This now accounts for $1 / 3$ of this young population (Tab. I). This is particularly important in relation to the level of knowledge about risk factors and prevention of HT and CVD. Our study shows that recently students more frequently identify salt as a CV-risk factor as compared to the year of 2000, but still, the same proportion of them uses additional salt in meals. In a recent survey only $22 \%$ of adolescent girls and $9.8 \%$ of boys met WHO recommendation on sodium intake (based on the sodium urine excretion) [22].

\section{Physical activity}

According to the World Health Organization recommendation, young people aged 5-17 should spend at least 60 minutes daily on physical activity [23]. Regular and time-efficient approach to physical activity has been associated with benefits in young people by improving glucose and fats metabolism, reduction of risk of chronic disease and enhancement of immune system [24]. Nowadays, access to places to engage in physical activity is increasing. We now demonstrate in our study that $73.4 \%$ of students report the engagement in out-of-school sport activities which is a substantially higher proportion as compared to the year of 2000 (Tab. I).

We observed a tendency to take up more types of sport by present-day youth. The awareness about the beneficial role of exercise among adolescents from Tricity high schools seems to be well widespread in 2016, comparing to the year 2000. On the contrary, the amount of time spent on physical activity does not change over the course of the past 15 years (5.6 vs. 5.5 hours per week in 2000 and 2016, respectively). Favorably, greater number of adolescents in 2016 claim to be active out of school but only onethird of them spend recommended time training (> 5 hours). According to Eurostat data only $57.3 \%$ of young people between the age of 15-24 engage in regular physical activity in 2008, this number has slightly improved in 2012 (68.2\%) [25]. In Poland in 2014 only $16.2 \%$ of $15-19$ years olds declared time spend on physical activity to be longer than 300 minutes (5 hours) a week, whereas almost 35\% did not participate in any form of sports [26]. It is important to mention that almost $25 \%$ of children who do not participate in sufficient amount of weekly sports activities share at least one more risk factor of the development of hypertension (overweight, family history) $[27,28]$. Interestingly, the majority of them is well educated about the preventive role of physical activity. 


\section{Dietary habits}

A balanced diet is well-known as a component of a healthy lifestyle and plays an important role in the prevention of cardiovascular diseases [29]. Therefore in the study, we examined closer eating habits among Tricity adolescents, concentrating on the two aspects: fruits and vegetable intake and fast food consumption.

The World Health Organization and Food and Agriculture Organization of the United Nation reports recommend adults and adolescents to consume at least five portions of fruits and vegetable a day [30]. Furthermore, it is proved that the diet rich in fruits and vegetables reduces blood pressure [31]. Our results show that the majority of adolescents in both groups is aware of diet rich in fruits and veggies preventive role in cardiovascular diseases, and claims to eat them frequently (Tab. I). Despite this fact, less than one in ten participants eats recommended number or more of fruits and vegetable servings per day.

Frequent fast food consumption is associated with a higher BMI in adolescents [32], therefore it might lead to higher cardiovascular risk [33]. In our study we observed the increase in awareness of excessive fat intake being a risk factor for obesity and hypertension between the year 2000 and 2016, reaching as much as $93.9 \%$ in 2016 (Tab. I). Unfortunately, this data has no reflection in lifestyle of both groups. Our data shows a significant grow in the percentage of adolescents who reported eating fast foods once a week or more, rising from $13.9 \%$ in the year 2000 to $44.8 \%$ in 2016. Unlike in the survey conducted in Lithuania were the consumption of fast foods among adolescents decreased from $13.1 \%$ and $16.4 \%$ in 2006 to $6.7 \%$ and $10.5 \%$ (girls and boys, respectively) in 2010 [34].

Our results might lead to the conclusion that in contradiction to a notable improvement in knowledge about healthy eating habits among Tricity adolescents, their habits in this area deteriorated significantly.

\section{Alcohol and smoking}

Analogously to studies in adulthood, it has been shown that adolescents' regular alcohol consumption increases blood pressure [35]. Of more, such behavior may contribute to the development of hypertension in adulthood [36]. In our study, the number of teenagers who were aware that excessive alcohol consumption might lead to hypertensive effect was greater in 2016 than fifteen years earlier. This may reflect the improvement in education in this particular area which is further supported by increased number of declared abstinence.

We noticed similar trends towards smoking reduction. Smaller proportion of children tried smoking at least once in their life in 2016 than in 2000. Moreover, the age at which students tried smoking for the first time has increased significantly in 2016 (Tab. I). It is worth mentioning that in our group the declared smoking status was present in $4 \%$ of students, what puts the reported smoking prevalence among the lowest in Europe [37]. This finding is in agreement with published data on smoking prevalence changes, between year 2009 and 2014 the prevalence of smoking decreased by nearly $2 \%$ in Poland [38]. The education about cigarettes smoking harmful effects has been improved but, most importantly, stroke and hypertension remain uncorrelated with this habit accurately in the perception of studied adolescents. Additionally, only half of students from 2016 reports having been informed by their doctor about the negative effects of smoking on their health.

\section{Hypertension and concomitant diseases}

Clearly, hypertension leads to target organ damage [4]. Uncontrolled high blood pressure increases risk of stroke, myocardial infarction and chronic kidney disease [39].

Over fifteen years the awareness of long-term consequences connected with HT increased in a studied population. However, the percentage of correct answers is satisfactory only in terms of MI and lower limbs atherosclerosis. Kidney diseases and stroke are still being ignored in terms of complications of HT.

\section{Strengths and weakness}

Strength of our study is the possibility to compare the pupils', on the verge of adulthood, perception of healthy behaviors between year 2000 and 2016 . This period of time is connected with the greatest development of internet-based technologies, changes in information distribution as well as a great shift in prevalence of cardiovascular risk factors among young people.

A possible bias of our results may be linked to declared rather than true anthropometrical data (results based on declared body weight and height).

\section{Conclusion}

To conclude, our study indicates that present-day adolescents from Tricity's high schools are better educated about the role of CV-risk factors, and the prevention measures than in the year 2000. Interestingly, the awareness of the link between $\mathrm{CV}$-risk factors such as hypertension and smoking with myocardial infarction was satisfactory, but it was insufficient for stroke and renal diseases. The number of declared smokers and first-time alcohol users among high-school adolescents 
is decreasing. Finally, the awareness of health-promoting behaviours such as regular physical activity, limited salt and fats intake, vegetables and fruits-based diet is common in this population but its implementation is insufficient (Tab. II).

\section{References}

1. Zdrojewski T, Wyrzykowski B, Szczech R, Wierucki L, Naruszewicz M, Narkiewicz K, Zarzeczna-Baran M. Epidemiology and prevention of arterial hypertension in Poland. http://dxdoiorg: 0803802050042905.

2. Gooding HC, McGinty S, Richmond TK, et al. Hypertension awareness and control among young adults in the national longitudinal study of adolescent health. J Gen Intern Med. 2014; 29(8): 1098-1104, doi: 10.1007/s11606-014-2809-x, indexed in Pubmed: 24577758.

3. Nguyen QC, Tabor JW, Entzel PP, et al. Discordance in national estimates of hypertension among young adults. Epidemiology. 2011; 22(4): 532-541, doi: 10.1097/EDE.0b013e31821c79d2, indexed in Pubmed: 21610501.

4. Tykarski A, Narkiewicz K, Gaciong Z, et al. 2015 guidelines for the management of hypertension. Recommendations of the Polish Society of Hypertension - short version. Kardiol Pol. 2015; 73(8): 676-700, doi: 10.5603/KP.2015.0157, indexed in Pubmed: 26304155.

5. Gorczyca-Michta I, Kucfir J, Wożakowska-Kapłon B. Factors predisposing to the occurrence of hypertension in a population of young adults. Folia Cardiologica. 2014; 9(2): 127-135.

6. Kulaga Z, Grajda A, Gurzkowska B, Wojtylo MA, Gozdz M, Litwin MS. The prevalence of overweight and obesity among Polish school-aged children and adolescents. Przegl Epidemiol 2016, 70(4):641-651.

7. Lauer RM, Clarke WR, Mahoney LT, et al. Childhood risk factors for high adult blood pressure: the Muscatine Study. Pediatrics. 1989; 84(4): 633-641, indexed in Pubmed: 2780125.

8. Brown IJ, Tzoulaki I, Candeias V, et al. Salt intakes around the world: implications for public health. Int J Epidemiol. 2009; 38(3): 791-813, doi: 10.1093/ije/dyp 139, indexed in Pubmed: 19351697.

9. Marrero NM, He FJ, Whincup P, et al. Salt intake of children and adolescents in South London: consumption levels and dietary sources. Hypertension. 2014; 63(5): 1026-1032, doi: 10.1161/HYPERTENSIONAHA.113.02264, indexed in Pubmed: 24614217.

10. Hublet A, De Bacquer D, Valimaa R, et al. Smoking trends among adolescents from 1990 to 2002 in ten European countries and Canada. BMC Public Health. 2006; 6: 280, doi: 10.1186/1471-2458-6-280, indexed in Pubmed: 17096837.

11. Krawczyk M, Czarniak P, Szcześniak P, et al. The prevalence of risk factors for atherosclerosis among middle school students in Sopot, Poland: results of the SOPKARD 15 programme. Kardiol Pol. 2011; 69(6): 540-545, indexed in Pubmed: 21678286.

12. Goniewicz ML, Gawron M, Nadolska J, et al. Rise in electronic cigarette use among adolescents in Poland. J Adolesc Health. 2014; 55(5): 713-715, doi: 10.1016/j.jadohealth.2014.07.015, indexed in Pubmed: 25344033.

13. Effect of the Age at Which Smoking Begins on Frequency of Smoking in Adulthood. http://dxdoiorg/101056/NEJM199109263251318 2010.

14. Okulicz-Kozaryn K, Borucka A. Warsaw adolescent alcohol use in a period of social change in Poland: cluster analyses of five consecutive surveys, 1988 to 2004. Addict Behav. 2008; 33(3): 439-450, doi: 10.1016/j.addbeh.2007.10.012, indexed in Pubmed: 18060701.

15. Okić R, Dobranić M. [Alcohol consumption in adolescence as predisposition for early development of alcohol addiction]. Med Arh. 2009; 63(2): 94-96, indexed in Pubmed: 19537665.

16. Kułaga Z., Palczewska I., Grajda A. i wsp. oraz Grupa Badaczy OLAF. Percentile charts of height, body mass and body mass index in children and adolescents in Poland - results of the OLAF study. Standardy Medyczne/Pediatria 2010; 7: 690-700.

17. Oblacińska A, Kołoło H, Mazur J. [Socio-economic determinants of physical development disorders among 15-year-olds in Poland]. Med Wieku Rozwoj. 2008; 12(2 Pt 1): 549-557, indexed in Pubmed: 19301503.
18. Szponar MO. Epidemiology of undernutrition in population of children and adolescents in Poland (PDF Download Available). Pediatria Wspolczesna. 2004; 6(1): 13-17.

19. Derezinski T, Wolf J, Szyndler A, et al. 3B.05: Comparison of incident hypertension, overweight and obesity in a representative Polish junior high-school population in 2005 vs. 2014. J Hypertens. 2015; 33 Suppl 1: e35, doi: 10.1097/01.hjh.0000467442.45988.4b, indexed in Pubmed: 26102800.

20. Brettschneider AK, Rosario AS, Ellert U. Validity and predictors of BMI derived from self-reported height and weight among 11- to 17-year-old German adolescents from the KiGGS study. BMC Res Notes. 2011; 4: 414, doi: 10.1186/1756-0500-4-414, indexed in Pubmed: 22005143.

21. WHO. WHO issues new guidance on dietary salt and potassium. WHO 2013

22. Gonçalves $\mathrm{C}$, Abreu S, Padrão P, et al. Sodium and potassium urinary excretion and dietary intake: a cross-sectional analysis in adolescents. Food Nutr Res. 2016; 60: 29442, indexed in Pubmed: 27072344.

23. WHO. Physical activity and young people. WHO 2015.

24. The health benefits of physical activity in children and adolescents: implications for chronic disease prevention. SpringerLink. 2017.

25. Łysioń P. Uczestnictwo Polaków w sporcie i rekreacji ruchowej. GUS, Warszawa 2013.

26. Time spent on health-enhancing (non-work-related) aerobic physical activity by sex, age and educational attainment level — Eurostat [http:// //ec.europa.eu/eurostat/web/products-datasets/-/hlth_ehis_pe2e]

27. Kelly RK, Magnussen CG, Sabin MA, et al. Development of hypertension in overweight adolescents: a review. Adolesc Health Med Ther. 2015; 6: 171-187, doi: 10.2147/AHMT.S55837, indexed in Pubmed: 26543386.

28. Ewald DR, Haldeman PhD LA. Risk Factors in Adolescent Hypertension. Glob Pediatr Health. 2016; 3: 2333794X15625159, doi: 10.1177/2333794X15625159, indexed in Pubmed: 27335997.

29. Srinath Reddy K, Katan MB. Diet, nutrition and the prevention of hypertension and cardiovascular diseases. Public Health Nutr. 2004; 7(1A): 167-186, indexed in Pubmed: 14972059.

30. Food-based dietary guidelines in the WHO European Region. ; 2014.

31. Appel LJ, Moore TJ, Obarzanek E, et al. A clinical trial of the effects of dietary patterns on blood pressure. DASH Collaborative Research Group. N Engl J Med. 1997; 336(16): 1117-1124, doi: 10.1056/ /NEJM199704173361601, indexed in Pubmed: 9099655.

32. Braithwaite I, Stewart AW, Hancox RJ, et al. ISAAC Phase Three Study Group, ISAAC Phase Three Study Group. Fast-food consumption and body mass index in children and adolescents: an international cross-sectional study. BMJ Open. 2014; 4(12): e005813, doi: 10.1136/ /bmjopen-2014-005813, indexed in Pubmed: 25488096.

33. Petkeviciene J, Klumbiene J, Kriaucioniene V, Raskiliene A, Sakyte E, Ceponiene I. Anthropometric measurements in childhood and prediction of cardiovascular risk factors in adulthood: Kaunas cardiovascular risk cohort study. BMC Public Health 2015, 15:218.

34. Zaborskis A, Lagunaite R, Busha R, et al. Trend in eating habits among Lithuanian school-aged children in context of social inequality: three cross-sectional surveys 2002, 2006 and 2010. BMC Public Health. 2012; 12: 52, doi: 10.1186/1471-2458-12-52, indexed in Pubmed: 22260778.

35. Le-Ha C, Beilin LJ, Burrows S, et al. Oral contraceptive use in girls and alcohol consumption in boys are associated with increased blood pressure in late adolescence. Eur J Prev Cardiol. 2013; 20(6): 947-955, doi: 10.1177/2047487312452966, indexed in Pubmed: 22790885.

36. Beilin LJ, Puddey IB. Alcohol and hypertension. 2006.

37. D'Angelo D, Ahluwalia IB, Pun E, et al. Current Cigarette Smoking, Access, and Purchases from Retail Outlets Among Students Aged 13-15 Years - Global Youth Tobacco Survey, 45 Countries, 2013 and 2014. MMWR Morb Mortal Wkly Rep. 2016; 65(34): 898-901, doi: 10.15585/mmwr.mm6534a3, indexed in Pubmed: 27584595.

38. Jakóbik K. Zdrowie kobiet w Polsce w latach 2004-2009. GUS, Kraków 2012.

39. Mancia G, Rea F, Cuspidi C, et al. Blood pressure control in hypertension. Pros and cons of available treatment strategies. J Hypertens. 2017; 35(2): 225-233, doi: 10.1097/HJH.0000000000001181, indexed in Pubmed: 27898507. 